\title{
Clinical application of infrared thoracoscopy to detect bullous or emphysematous lesions of the lung
}

Masashi Gotoh, MD, Yasumichi Yamamoto, MD, Hitoshi Igai, MD, Sungsoo Chang, MD, Chenglong Huang, MD, and Hiroyasu Yokomise, MD

From the Second Department of Surgery, Faculty of Medicine, Kagawa University, Kagawa, Japan.

Received for publication May 24, 2007; accepted for publication July 5, 2007.

Address for reprints: Hiroyasu Yokomise, MD, Second Department of Surgery, Faculty of Medicine, Kagawa University, 1750-1, Ikenobe, Miki, Kita-gun, Kagawa 761-0793 Japan (E-mail: yokomise@kms.ac.jp).

J Thorac Cardiovasc Surg 2007;134:1498-501 $0022-5223 / \$ 32.00$

Copyright (๑) 2007 by The American Association for Thoracic Surgery

doi:10.1016/j.jtcvs.2007.07.051
Objective: We have previously reported that infrared thoracoscopy was useful in detecting emphysematous lesions in a canine model of lung emphysema. We applied infrared thoracoscopy to determine the feasibility and efficacy of planning bullectomy for patients with spontaneous pneumothorax.

Methods: A total of 8 patients with spontaneous pneumothorax were included in the study. No procedure-related complications were observed. Infrared thoracoscopy with a single injection of indocyanine green $(3.0 \mathrm{mg} / \mathrm{kg})$ was used to detect bullous lesions of the lung during surgical intervention. Partial lung resections of the bullous lesions were performed after image analysis based on color density data obtained by means of infrared thoracoscopy.

Results: Bullous or emphysematous lesions of the lung were demonstrated in white, whereas normal lung tissue was imaged in blue, under infrared thoracoscopy. We were able to detect small bullous lesions with infrared thoracoscopy because of its clearer visualization compared with thoracoscopy. Quantitative color-density analysis revealed a marked decrease of indocyanine green intensity, which reflected decreased blood flow of bullous lesions. All resected specimens were confirmed as bullous lesions based on microscopic examinations.

Conclusion: Infrared thoracoscopy-guided lung resection is a safe and useful procedure in detecting small bullous lesions.

$\mathrm{B}$ ullectomy under video-assisted thoracoscopic surgery (VATS) has been used as an accepted procedure for patients with spontaneous pneumothorax. ${ }^{1,2}$ However, the higher recurrence rate of pneumothorax after VATS than the rate after standard thoracotomy remains an issue for improvement.

Previously, we have reported that infrared thoracoscopy (IRT) with intravenous injection of indocyanine green (ICG) was useful for detecting emphysematous areas in an experimental animal model. ${ }^{3,4}$ Accurate and real-time detection of bullous or emphysematous lungs during surgical intervention is essential for bullectomy. Here we report our clinical experiences with IRT to detect bullous and emphysematous lung regions during thoracoscopy.

\section{Materials and Methods}

A total of 8 patients with spontaneous pneumothorax were included in the study. The study protocol was approved by the Research Ethics Board of Kagawa University Hospital, Japan. Written informed consent was obtained from all patients. The patients were all male, and the 

Abbreviations and Acronyms
$\mathrm{CDR}=$ color density ratio
ICG = indocyanine green
IRT = infrared thoracoscopy
VATS $=$ video-assisted thoracoscopic surgery

mean age was 26 years (range, 17-43 years). All patients were confirmed to have no drug allergy to iodine or ICG.

After achievement of general anesthesia, patients underwent VATS for bullectomy. IRT imaging was used for visualization of bullous lesions during the operation. Initially, the lung was observed under normal white light and then observed under IRT with intravenous injection of $3.0 \mathrm{mg} / \mathrm{kg}$ ICG. After IRT observation, all surgical procedures were done under normal light, as with usual VATS bullectomy. Surgical specimens were submitted for pathologic examination.

The colors visualized by means of IRT reflect the degree of blood flow, which correlates with the lung parenchymal destruction of emphysematous diseases. ICG is visualized in blue color when it is detected by means of IRT. Therefore the areas with decreased blood flow are visualized as white in color, whereas normal lung areas (ie, lung tissue with normal blood flow) are visualized as blue (Figure 1).

The IRT images were analyzed with Lumina Vision (Mitani Co, Fukui, Japan) in 3 patients. Color density ratios (CDRs) were calculated as previously described, ${ }^{3}$ dividing green or red color density by blue color density.

\section{Results}

No perioperative and postoperative complications were observed.

The time periods of transient color visualization are summarized in Table 1. The normal lung tissue started being visualized in blue from 10 to 20 seconds (mean,

TABLE 1. Summary of visualized time periods of infrared thoracoscopy and detection of bullous lesion by means of infrared thoracoscopy

\begin{tabular}{|c|c|c|c|c|c|c|c|}
\hline \multirow[b]{2}{*}{$\begin{array}{l}\text { Case } \\
\text { no. }\end{array}$} & \multirow[b]{2}{*}{$\begin{array}{l}\text { Age } \\
\text { (y) }\end{array}$} & \multirow[b]{2}{*}{ Sex } & \multirow{2}{*}{$\begin{array}{l}\text { Time } \\
\text { to } \\
\text { dye(s) }\end{array}$} & \multirow[b]{2}{*}{$\begin{array}{c}\text { Deepest } \\
\text { contrast(s) }\end{array}$} & \multirow{2}{*}{$\begin{array}{c}\text { Possible } \\
\text { observation } \\
\text { time(s) }\end{array}$} & \multicolumn{2}{|c|}{$\begin{array}{l}\text { Detection of } \\
\text { bullae }\end{array}$} \\
\hline & & & & & & $\begin{array}{c}\text { Normal } \\
\text { light }\end{array}$ & IRT \\
\hline 1 & 20 & $M$ & 20 & 30 & 200 & Well & Well \\
\hline 2 & 20 & $M$ & 10 & 19 & 180 & Poor & Well \\
\hline 3 & 31 & $M$ & 16 & 25 & 170 & Well & Well \\
\hline 4 & 34 & $M$ & 16 & 28 & 180 & Well & Well \\
\hline 5 & 43 & $\mathrm{M}$ & 13 & 25 & 210 & Poor & Well \\
\hline 6 & 24 & $M$ & 13 & 25 & 150 & Well & Well \\
\hline 7 & 17 & $\mathrm{M}$ & 20 & 30 & 200 & Well & Well \\
\hline 8 & 21 & $M$ & 13 & 18 & 160 & Poor & Well \\
\hline
\end{tabular}

$I R T$, Infrared thoracoscopy.
15.1 seconds) after ICG injection and lasted up to 210 seconds (mean, 181.3 seconds). The areas with bullous change were demarked clearly in white so that surgeons were able to recognize the lesions. Especially in 3 of 8 cases, in which bullous lesions were poorly detectable under normal white light, IRT could effectively visualize the bullous lesion.

The resected lesions corresponded to the area that was visualized in white by means of IRT, and its specimens showed bullous changes, emphysematous changes, or both microscopically. CDRs of resected lung tissue were less than 1.0 .

\section{Patient 1}

IRT was performed on a 20-year-old man with spontaneous pneumothorax. Some small bullae were easily detected under white light, and these bullae were observed as white by means of IRT; meanwhile, normal lung tissue was observed as blue (Figure 2). The normal lung tissue became blue 8 seconds after injection of ICG, and the blue-white contrast lasted for 180 seconds.

\section{Patient 2}

IRT was performed on a 20-year-old man with spontaneous pneumothorax. Bullous regions could not be detected easily under white light. With IRT, a bullous region appeared as white (Figure 3), and image analysis revealed fine changes of color tone (Figure 4). Resected lung tissue was microscopically confirmed as a bulla (Figure 5), and the CDR of the resected lung tissue was less than 1.0.

\section{Discussion}

VATS bullectomy has been used for patients with spontaneous pneumothorax as an accepted procedure. However, the higher recurrence rate of pneumothorax after VATS than after standard thoracotomy remains an issue on which to improve. Failure to identify bullous lesions was considered a reason for the higher recurrence rate. Accurate and real-time identification of bullous or emphysematous lung tissue is essential for bullectomy. IRT can visualize blood flow in the lungs, and thus we have reported that IRT with intravenous ICG was useful for detecting emphysematous areas in an animal experimental model. ${ }^{3,4}$

ICG is a tricarbocyanine dye that has been used in measuring cardiac output and liver function. Intravenously injected ICG is bound rapidly to serum proteins and excreted in bile without being metabolized. ${ }^{5,6}$ According to toxicity studies, $5.0 \mathrm{mg} / \mathrm{kg}$ ICG intravenous injection is quite safe and permissible. ${ }^{7}$ We injected $3.0 \mathrm{mg} / \mathrm{kg}$ ICG intravenously in this study, and no acute or chronic toxici- 


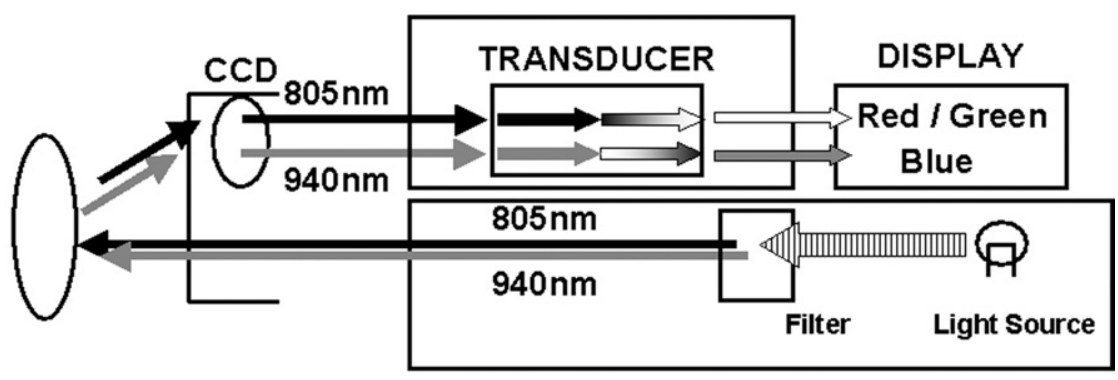

A

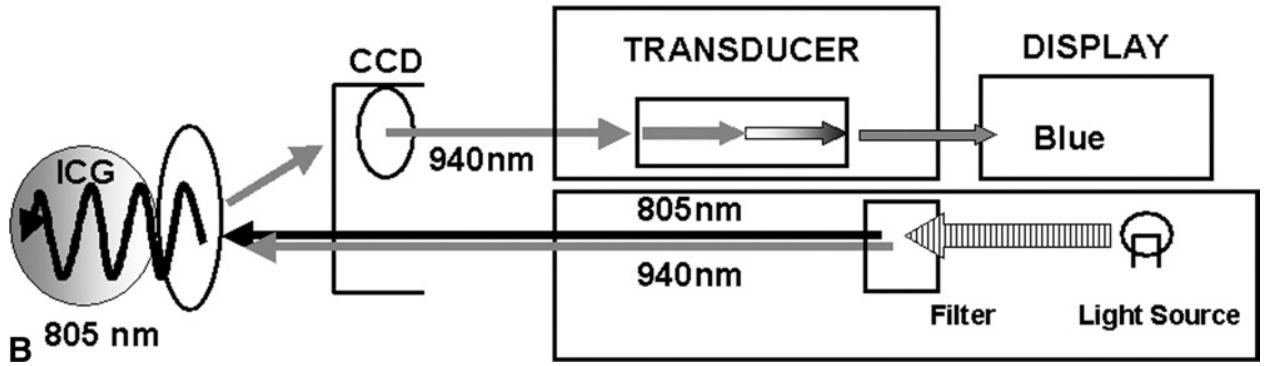

Figure 1. System of infrared thoracoscopy. Without indocyanine green (ICG), infrared light at a wavelength of 950 and $805 \mathrm{~nm}$ is reflected, and the object is displayed as white (A). With ICG, the ICG absorbs the $805 \mathrm{~nm}$ of light, and the object is displayed as blue (B). CCD, charge-coupled device.

ties or any other side effects relevant to ICG injection were found.

Resected lung specimens, which corresponded to the white area under IRT, were microscopically revealed as bullae or emphysematous lung tissue. The tissue density of emphysematous and bullous lung tissue is lower than that of normal lung tissue, and thus blood flow is also decreased compared with that seen in the normal lung. IRT could detect and visualize this difference of blood flow similar to a perfusion scan.

Blue-white contrast lasted for 3 to 5 minutes but subsequently diminished. The possible observation period is relatively short for detailed observation of the whole lung. Moreover, additional ICG injection could not be done because its maximum dose was not clear, and thus we combined image analysis to evaluate the whole lung.

Image analysis could detect fine changes of color tone and evaluate the color tone quantitatively. Although which CDR best divides normal from emphysematous lung tissue should be examined, IRT combined with image analysis might be a useful procedure, especially in VATS lung volume reduction surgery, in which the need exists to distinguish severe emphysematous areas among heterogeneous emphysema.

\section{Conclusions}

IRT with intravenous injection of ICG is a clinically rapid and safe method to detect bullous and emphysematous regions of the lung in human subjects. IRT combined with image analysis can be an effective intraoperative method to evaluate heterogeneous emphysema.

\section{References}

1. Inderbitzi RG, Leiser A, Furrer M, Althaus U. Three years' experience in video-assisted thoracic surgery (VATS) for spontaneous pneumothorax. J Thorac Cardiovasc Surg. 1994;107:1410-5.

2. Naunheim KS, Mack MJ, Hazelrigg SR, et al. Safety and efficacy of video-assisted thoracic surgical techniques for the treatment of spontaneous pneumothorax. J Thorac Cardiovasc Surg. 1995;109:1198203.

3. Gotoh M, Okamoto T, Yamamoto Y, Yokomise H. Real time imaging and quantitative evaluation of the emphysematous lung by infrared thoracoscopy in experimental dogs. ASAIO J. 2005;51:148-51.

4. Gotoh M, Okamoto T, Yamamoto Y, et al. Development of a canine model of pulmonary emphysema and imaging of the emphysematous lung with infrared thoracoscopy. J Thorac Cardiovasc Surg. 2003;126: 1916-21

5. Caesar J, Shaldon S, Chiandussi L, Guevara L, Sherlock S. The use of indocyanine green in the measurement of hepatic blood flow and as a test of hepatic function. Clin Sci. 1961;21:43-57.

6. Cherrick GR, Stein SW, Leevy CM, Davidson CS. Indocyanine green: observations on its physical properties, plasma decay, and hepatic extraction. J Clin Invest. 1960;39:592-600.

7. Fox IJ, Wood EH. Indocyanine green: physical and physiologic properties. Mayo Clin Proc. 1960;35:732-44. 


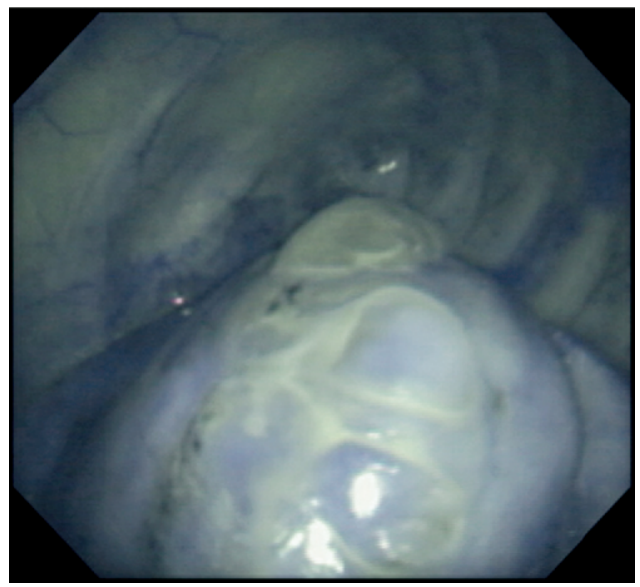

Figure 2. Infrared thoracoscopic images with indocyanine green injection. Bullae were observed as white, whereas normal lung tissue was observed as blue (patient 1).

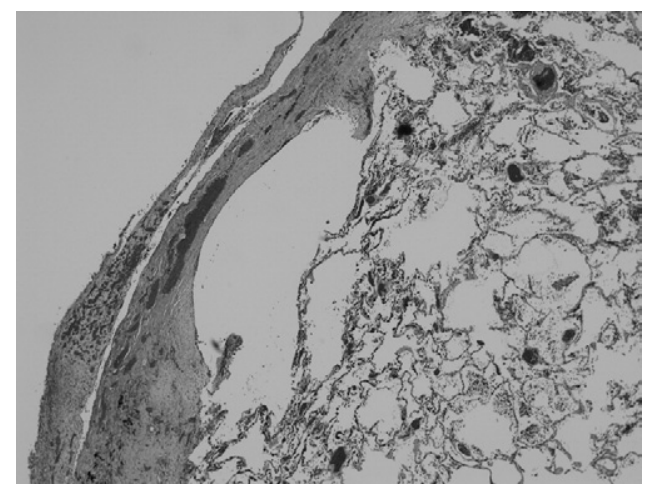

Figure 5. Microscopic finding of resected lung tissue showed bullous features (patient 2).
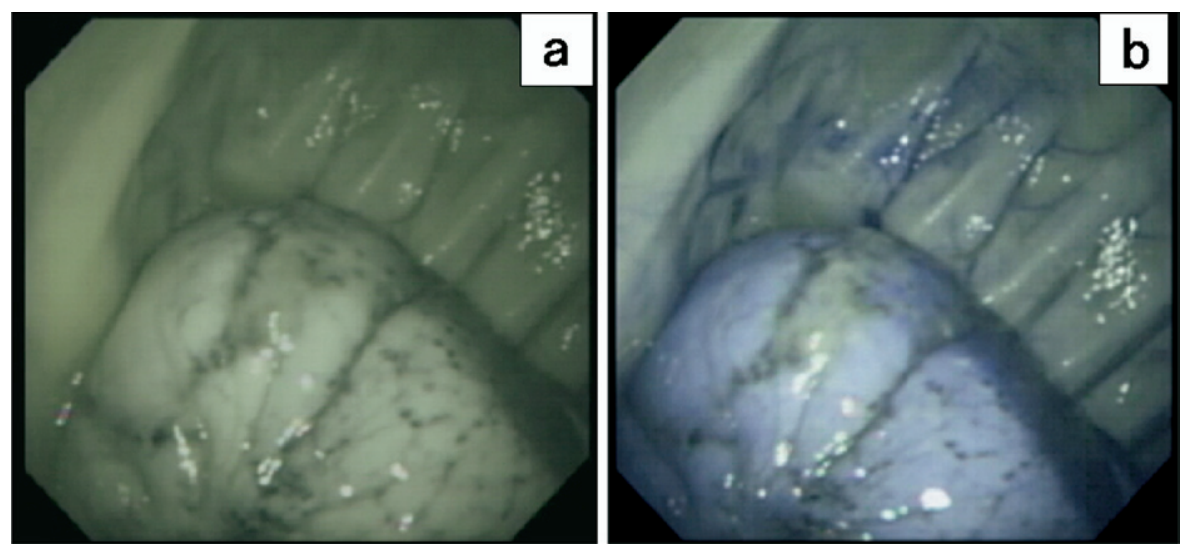

Figure 3. Thoracoscopic images observed under normal light (A) and infrared light with indocyanine green injection (B). A bulla and emphysematous lung tissue were observed as white, whereas the normal lung tissue was observed as blue by means of infrared thoracoscopy with indocyanine green injection (case 2).
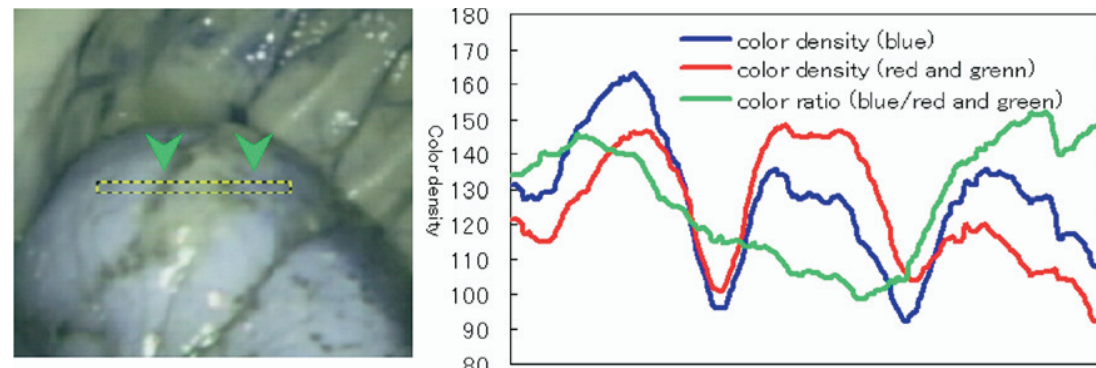

1.4

Figure 4. The sampling area shown as a yellow rectangle was selected along the blue-white boundary zone, and the color densities and color density ratio were measured. The $X$-axis was matched with the long axis of the sampling area. Green arrows demonstrate the point at which the color density ratio is 1.0 . 